\title{
Tbx2 mediates dorsal patterning and germ layer suppression through inhibition of BMP/GDF and Activin/Nodal signaling
}

\author{
Shoshana Reich ${ }^{1}$, Peter Kayastha ${ }^{2}$, Sushma Teegala ${ }^{2}$ and Daniel C. Weinstein ${ }^{1,2^{*}}$ (D)
}

\begin{abstract}
Background: Members of the T-box family of DNA-binding proteins play a prominent role in the differentiation of the three primary germ layers. VegT, Brachyury, and Eomesodermin function as transcriptional activators and, in addition to directly activating the transcription of endoderm- and mesoderm-specific genes, serve as regulators of growth factor signaling during induction of these germ layers. In contrast, the T-box gene, tbx2, is expressed in the embryonic ectoderm, where Tbx2 functions as a transcriptional repressor and inhibits mesendodermal differentiation by the TGF $\beta$ ligand Activin. Tbx2 misexpression also promotes dorsal ectodermal fate via inhibition of the BMP branch of the TGF $\beta$ signaling network.

Results: Here, we report a physical association between Tbx2 and both Smad1 and Smad2, mediators of BMP and Activin/Nodal signaling, respectively. We perform structure/function analysis of Tbx2 to elucidate the roles of both Tbx2-Smad interaction and Tbx2 DNA-binding in germ layer suppression.

Conclusion: Our studies demonstrate that Tbx2 associates with intracellular mediators of the Activin/Nodal and BMP/GDF pathways. We identify a novel repressor domain within Tbx2, and have determined that Tbx2 DNAbinding activity is required for repression of TGF $\beta$ signaling. Finally, our data also point to overlapping yet distinct mechanisms for Tbx2-mediated repression of Activin/Nodal and BMP/GDF signaling.
\end{abstract}

Keywords: Xenopus, Development, Gastrulation, Ectoderm, Gene regulation, Tbx2, Smads

\section{Background}

Understanding the development of an embryo from a single totipotent cell to a highly differentiated, multicellular organism is a foundational concern of developmental biology. In triploblasts, three embryonic germ layers, ectoderm, mesoderm, and endoderm, give rise to virtually all tissue types. The endodermal germ layer differentiates into pancreas, liver, lung, and other components of the digestive and respiratory systems. The mesodermal layer gives rise the muscular, circulatory, and

\footnotetext{
* Correspondence: daniel.weinstein@qc.cuny.edu

'The Graduate Center, The City University of New York, New York, NY 10016, USA

2Department of Biology, Queens College, The City University of New York, Queens, NY 11367, USA
}

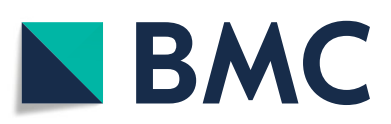

(c) The Author(s). 2020 Open Access This article is licensed under a Creative Commons Attribution 4.0 International License, which permits use, sharing, adaptation, distribution and reproduction in any medium or format, as long as you give appropriate credit to the original author(s) and the source, provide a link to the Creative Commons licence, and indicate if changes were made. The images or other third party material in this article are included in the article's Creative Commons licence, unless indicated otherwise in a credit line to the material. If material is not included in the article's Creative Commons licence and your intended use is not permitted by statutory regulation or exceeds the permitted use, you will need to obtain permission directly from the copyright holder. To view a copy of this licence, visit http://creativecommons.org/licenses/by/4.0/. The Creative Commons Public Domain Dedication waiver (http://creativecommons.org/publicdomain/zero/1.0/) applies to the data made available in this article, unless otherwise stated in a credit line to the data. crest, and cranial sensory placodes derive from ectoderm. The precise coordination of germ layer differentiation is, by definition, crucial for normal embryogenesis.

During vertebrate development, the formation and patterning of the three germ layers is a rapid and tightly regulated process; studies in the frog Xenopus laevis have been essential for our understanding of these processes. An initiating step in development of the germ layers occurs when VegT, a maternally supplied transcription factor, directly initiates an endoderm-specific gene expression program among cells located in the vegetal pole [1]. VegT also activates nodal and nodal-related gene expression; these transcripts encode proteins that induce cells in the region adjacent to the vegetal 
pole, in the so-called marginal zone, to differentiate into mesoderm [2, 3]. In this VegT-centric model of germ layer formation, differentiation in the animal pole is the consequence of an absence of both extracellular signaling and germ layer-specific transcriptional activation -VegT is not expressed in this region, and it is far from the source of Nodal signaling; thus, neither endodermal nor mesodermal differentiation ensues, and ectoderm forms in the animal pole "by default" $[4,5]$.

Recently, however, it has become clear that the suppression of inappropriate cell fate also plays a critical role in germ layer determination in the vertebrate embryo [6]. Several proteins have been implicated in mesendodermal suppression in the ectoderm. For example, coco (dand5), a maternally supplied transcript, encodes an inhibitor of TGF $\beta$ signaling $[7,8]$. Depletion of Coco in the animal cap explant results in ectopic mesodermal formation [7]. Another protein identified as a suppressor of mesendoderm is the Foxi-class transcription factor Xema/Foxile. Knockdown of foxile in animal cap explants leads to an increase in the expression of mesendodermal markers [9]. Moreover, ectopic expression of Foxile in the marginal zone inhibits mesoderm development. Foxile is a transcriptional activator, and is thus not expected to directly repress mesendodermal gene expression; instead, Foxile likely stimulates expression of genes encoding repressor protein(s) that is/are responsible for suppressing ectopic mesendoderm in the animal pole [9]. We recently identified $t b \times 2$, encoding the repressor T-box protein Tbx2, as one such candidate target of Foxile [10].

T-box proteins are an evolutionarily conserved family of transcription factors critical for a number of processes during development [11]. The first identified T-box protein, $\mathrm{T}$, encoded by brachyury, induces mesoderm in the early mammalian embryo [12]. In the mouse, a homozygous loss-of-function mutation in brachyury is embryonically lethal, highlighting the importance of T-box proteins in early development [13]. T-box proteins have also been implicated in development of craniofacial tissue, liver, heart, and lung [3, 14-17].

The T-box proteins are comprised of five subfamilies; all contain a highly conserved region of 180-200 amino acids, called the T-box, which confers DNA binding specificity $[18,19]$. Many T-box proteins have been shown to bind the core T-box binding element TCACACCT [19]. T-box proteins bind to DNA as either monomers or dimers, depending on the protein, and can function as activators or repressors of transcription [20]. Activator and repressor domains have been identified in the carboxyl (C)- or amino (N)- termini of T-box proteins [21, 22].

Two well-studied T-box proteins, VegT and Brachyury, are necessary for formation and patterning of endoderm and mesoderm, respectively; both function as transcriptional activators in this context $[3,23]$. Our lab has recently shown that Tbx 2 functions in the ectoderm as a transcriptional repressor during gastrulation [10]. When $t b x 2$ is knocked down in the presumptive ectoderm, ectopic mesendoderm forms; moreover, ectopic Tbx2 suppresses mesendoderm in animal cap explants exposed to Activin or basic Fibroblast Growth Factor (bFGF) [10]. To date, however, little is known about the mechanisms through which Tbx2 promotes repressor activity.

The population of cells in the ectoderm develops into several distinct tissue types. Ventral ectoderm differentiates into epidermis, while the dorsal ectoderm gives rise to neural tissue [24]; cells at the border of these two populations develop into the sensory placodes and neural crest $[25,26]$. Bone Morphogenetic Protein-4 (BMP-4), expressed throughout the ectoderm, ventralizes the ectoderm, which subsequently differentiates into epidermis [27]. Dorsally, at the initiation of gastrulation, the Spemann organizer secretes BMP antagonists allowing proximal ectodermal cells to adopt a dorsal, neural fate [27]. Tbx2 misexpression also dorsalizes ectoderm, resulting in neuralization; this effect is accompanied by downregulation of Bone Morphogenetic Protein (BMP) activity [10].

Tbx2 thus appears to suppress signaling through both the Activin/Nodal and BMP/GDF branches of the TGF $\beta$ pathway. In canonical TGF $\beta$ signaling, upon ligand binding, the TGF $\beta$ type II receptor phosphorylates the TGF $\beta$ type I receptor, which propagates the signal and phosphorylates the carboxyl terminus of the intracellular signal transducers Smad1/5 or Smad2/3, downstream of $\mathrm{BMP} / \mathrm{GDF}$ or Activin/Nodal ligands, respectively [28, 29]. These receptor-mediated Smads then form a heteromeric complex with Smad4 which translocates to the nucleus where it associates with transcription factors to regulate gene expression [28].

The discovery that Tbx2 has a global impact on TGF $\beta$ signaling prompted us to examine more directly the relationship between Tbx2 and components of the Activin/ Nodal and BMP/GDF networks. Here we report that Tbx2 physically associates with both Smad1 and Smad2, essential intracellular mediators of BMP and Nodal signaling, respectively. Deletion analysis of the Tbx2 protein identified the T-box DNA-binding domain as sufficient for Tbx2-Smad binding. Structure-function analyses suggest a model in which Tbx2 regulates interaction of Smads and Smad-interacting proteins in the nucleus.

\section{Results}

Tbx2 physically associates with multiple Smad proteins We have previously reported that Tbx2 inhibits mesoderm induction in animal cap explants treated with 
either basic Fibroblast Growth Factor (bFGF) or the TGF $\beta$ ligand Activin [10]. We find that misexpression of Tbx2 also inhibits expression of the panmesodermal marker brachyury in ventral and dorsal marginal zone explants, indicating that Tbx2 represses mesoderm formation in the context of the embryo (Fig. 1) [30]. Notably, ventral marginal zone explants show an increase in the dorsal markers chordin and goosecoid and repression of the ventral marker wnt8, demonstrating that Tbx2 has a dorsalizing effect on the mesoderm, as well as the ectoderm [10, 31-33] (Fig. 1). These and earlier published studies suggest that Tbx2 inhibits both Activin/Nodal and BMP/GDF signaling in the early embryo [10]. This raised the prospect that Tbx 2 may inhibit TGF $\beta$ signaling via direct interaction with TGF $\beta$ signaling transducers.

To address this possibility of direct interaction between Tbx2 and intracellular components of the TGF $\beta$ signaling network, we first examined whether Tbx2 physically associates with the Smad1 and Smad2 proteins, branch-specific mediators of BMP/GDF and Activin/Nodal signaling, respectively. As we have not

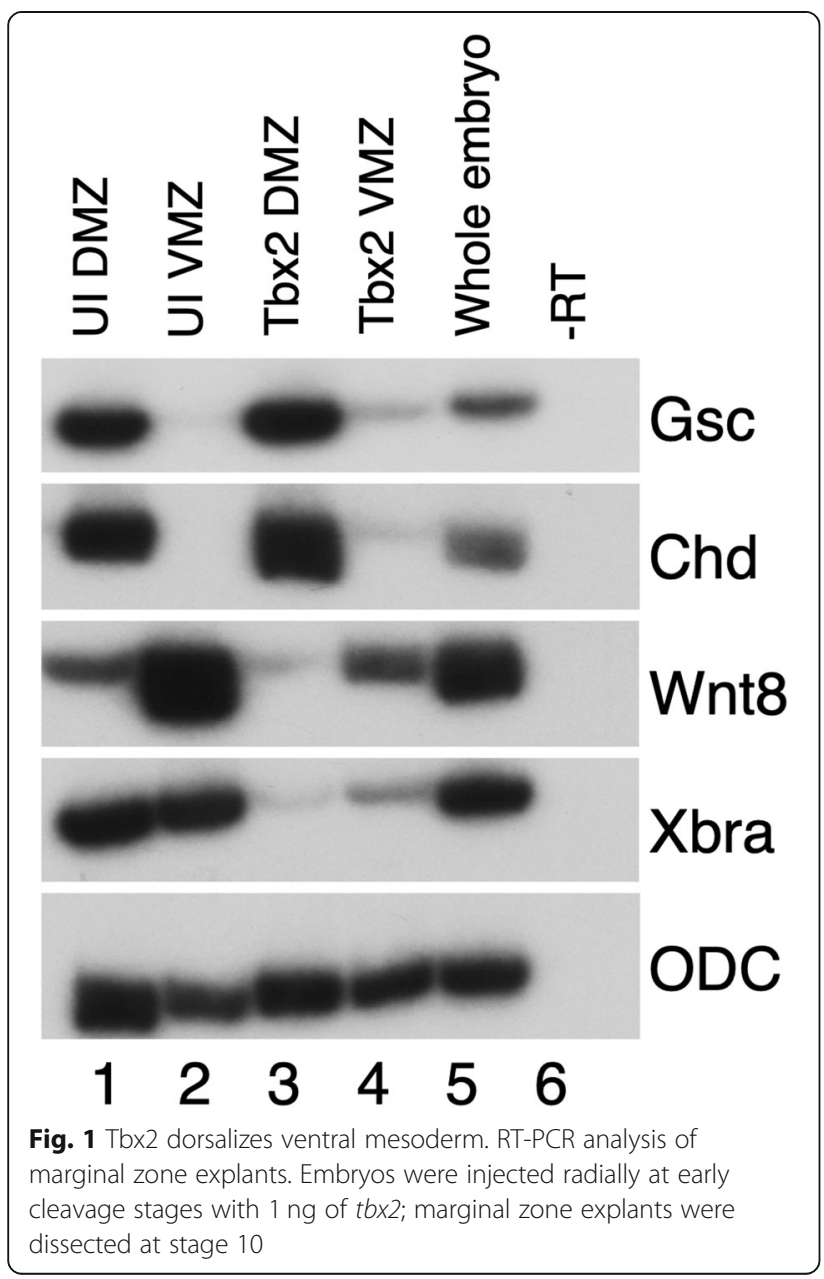

been able to obtain an antibody that recognizes native Tbx2, we generated a Myc-epitope-tagged Tbx2 construct (Myc-Tbx2), and injected myc-tbx2 synthetic RNA into early cleavage stage embryos. Immunoprecipitation and Western blot analysis demonstrated that native Smad1 physically associates with exogenous Tbx 2 in Xenopus embryos (Fig. 2a). We have not been able to detect native Xenopus Smad2 following immunoprecipitation using commercially-available antibodies; thus, we next co-injected $m y c-t b x 2$ and flag-smad2 synthetic RNA into early cleavage stage embryos. Physical association between exogenous Smad2 and Tbx2 in Xenopus laevis embryos was observed (Fig. 2b). Tbx2 inhibits mesodermal marker gene expression stimulated by Smad2, consistent with a physiological role for Tbx2Smad2 interaction during germ layer differentiation (Fig. 2c).

Following pathway-specific activation, both branches of the TGF $\beta$ pathway converge on the "co-Smad" Smad4, which associates with C-terminally phosphorylated forms of both Smad1 and Smad2 [34]. As with Smad1 and Smad2, exogenous Tbx2 physically associates with Flag epitope-tagged human Smad4 (Fig. 2d). Taken together, these studies demonstrate that Tbx2 associates with both pathway-specific and pathway-shared Smad proteins. Additionally, these data indicate that Tbx2 is unlikely to inhibit TGF $\beta$ signaling via sequestration of R-Smads from Smad4.

\section{Identification of the Tbx2 domain sufficient for R-Smad association}

Our determination of interactions between Tbx2 and Smad proteins prompted us to ask whether these associations are central to Tbx2's role in suppression of dorsal and/or extraectodermal fate. To determine whether Tbx2 requires interaction with Smad1 and Smad2 to mediate dorsoventral patterning or mesendodermal suppression, respectively, we first sought to identify the domains of Tbx2 protein required for Smad interaction. Toward this end, we constructed multiple Tbx2 deletion constructs, tagged with a Myc epitope (Fig. 3). These deletion constructs were designed so that each construct lacks one or more domains of Tbx2, with the goal of eliminating the region necessary for R-Smad interaction. Following injection of RNA encoding these constructs, we performed immunoprecipitation assays using either a Smad1 antibody or, after co-injection of $m y c-t b x 2$ and flag-smad2, a Flag epitope-specific antibody, followed by SDS-PAGE and Western blotting with an anti-Myc antibody. These studies identify the T-box region as sufficient for association with either Smad1 or Smad2; deletion of the $\mathrm{N}$ or $\mathrm{C}$ termini had no effect on R-Smad association. Tbx2 constructs with the first or second 
A

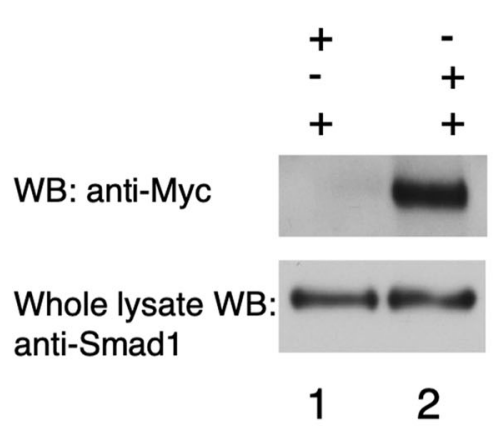

C

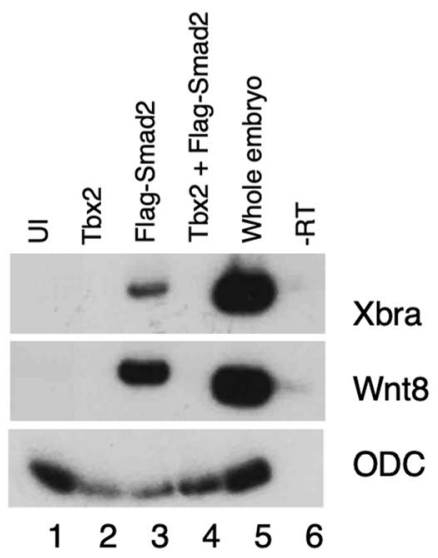

B

\begin{tabular}{|c|c|c|}
\hline & $\begin{array}{ll}+ & - \\
- & + \\
+ & + \\
+ & +\end{array}$ & $\begin{array}{l}\text { IP: IgG contro } \\
\text { IP: anti-Flag } \\
\text { Flag-Smad2 } \\
\text { Myc-Tbx2 }\end{array}$ \\
\hline WB: anti-Myc & 0 & \\
\hline $\begin{array}{l}\text { Whole lysate WB: } \\
\text { anti-Flag }\end{array}$ & -- & \\
\hline & 12 & \\
\hline
\end{tabular}

D

WB: anti-Myc

Whole lysate WB: anti-Flag

Fig. 2 Tbx2 associates with R-Smads a). Tbx2 physically associates with Smad1. 1 ng myc-tbx2 RNA was injected at early cleavage stages. Pulldown of native Smad1 from injected embryos leads to co-immunoprecipitation of exogenous Tbx2. Normal rabbit lgG antibodies were used in parallel studies as a negative control. b Tbx2 physically associates with Smad2. 1 ng of myc-tbx2 and $1 \mathrm{ng}$ of flag-smad2 were injected at early cleavage stages. Pull-down of Flag-Smad2 from injected embryos leads to co-immunoprecipitation of exogenous Tbx2. Normal rabbit IgG antibodies were used in parallel studies as a negative control c) Tbx2 represses Smad2-mediated mesoderm induction. Embryos were injected with tbx2 (1 ng), flag-smad2 (1 ng), or tbx2 (1 ng) and flag-smad2 (1 ng) at the two-cell stage and animal caps were explanted at stage 8.5. d Tbx2 physically associates with Smad4. 1 ng of myc-tbx2 and $1 \mathrm{ng}$ of flag-smad4 were injected at early cleavage stages. Pull-down of Flag-Smad4 from injected embryos leads to co-immunoprecipitation of of exogenous Tbx2. Normal rabbit lgG antibodies were used in parallel studies as a negative control

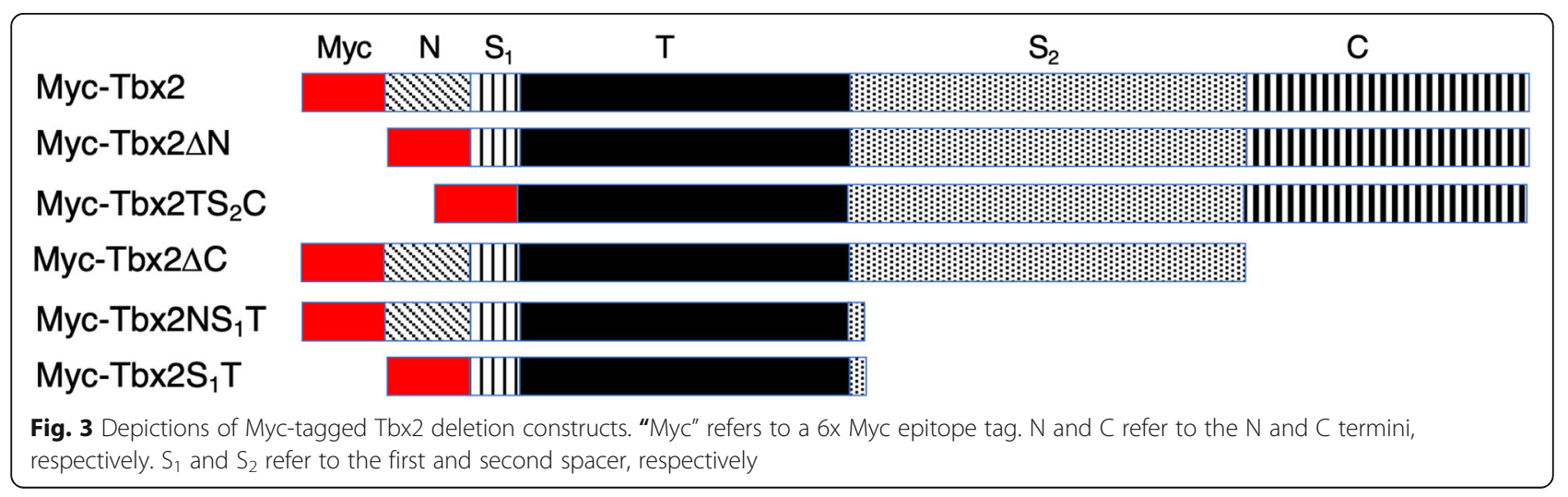


spacer deleted also associated with both Smad1 and Smad2 ((Fig. 4a-j).

\section{Activity of deletion constructs}

Because the region of Smad association is within the Tbox, we questioned whether the smallest construct that contained the T-box has activity. We expected this construct, $\mathrm{Tbx}_{2} \mathrm{~S}_{1} \mathrm{~T}$, to function, if at all, like $\mathrm{Tbx} 2 \Delta \mathrm{C}$ as both lack a previously identified $\mathrm{C}$-terminal repressor domain. Previous work from our lab showed that $\mathrm{Tbx} 2 \Delta \mathrm{C}$ does not repress Activin-mediated mesoderm expression [10]. To test the activity of $\mathrm{Tbx}_{2} \mathrm{~S}_{1} \mathrm{~T}$, we used an embryological assay. Animal caps were explanted at stage 8.5 from embryos injected at the 2-cell stage with RNA transcribed from Tbx $2 \mathrm{~S}_{1} \mathrm{~T}$ and cultured until stage 11 in the presence or absence of Activin. These samples were then assayed for mesodermal gene expression. To our surprise, this construct repressed Smad2/Activinmediated mesoderm induction in animal caps, suggesting the presence of a second, previously unidentified repressor domain in $\mathrm{Tbx}_{2} \mathrm{~S}_{1} \mathrm{~T}$ (Fig. 5a). Unlike fulllength Tbx2, misexpression of this construct did not repress all ventral markers; vent 2 was not repressed, while repression of $s z l$ was sometimes observed, indicating that complete ventral repression may require an as-yet undefined composite of domains (Fig. 5a, data not shown). Alternatively, it is possible that a higher concentration of $t b \times 2 S_{1} T$ is required for ventral than for mesodermal repression.

This result led us to question why the presumed second Smad2/Activin repressor domain is not active in $\mathrm{Tbx} 2 \Delta \mathrm{C}$. We hypothesize that there is a region present in $\mathrm{Tbx} 2 \Delta \mathrm{C}$ that functions as either an activator domain or an inhibitor of the second repressor domain. To test this possibility, we injected RNA transcribed from the construct missing both the $\mathrm{C}$-terminus and the second spacer, Tbx $2 \mathrm{NS}_{1} \mathrm{~T}$, into two-cell stage embryos. Animal caps were explanted at stage 8.5 and cultured in the presence or absence of Activin. Animal caps injected with $t b x 2 N S_{1} T$ RNA did not repress Activin-mediated mesoderm induction or ventral markers (Fig. 5b, c). These data supports our hypothesis, and indicates that the presence of the $\mathrm{N}$-terminus inhibits activity of the repressor located in Tbx $2 \mathrm{~S}_{1} \mathrm{~T}$. Deletion of only the $\mathrm{N}$ terminus has no effect on Tbx2 activity; animal caps explanted from embryos injected with RNA transcribed from $\mathrm{Tbx} 2 \Delta \mathrm{N}$ did not express mesodermal markers in the presence of Activin (Fig. 5d). Finally, RNA transcribed from $\mathrm{Tbx}_{2} \mathrm{TS}_{2} \mathrm{C}$, was injected and assayed for activity. This construct functions like the full length Tbx2 in both the Smad1/BMP and Smad2/Activin pathways (Fig. 5e). These results indicate that a construct containing the T-box, second spacer, and C-terminus renders the $\mathrm{N}$-terminus and the first spacer unnecessary for wild-type repression of both the Activin/Nodal and BMP/GDF pathways (Fig. 5e).

\section{Tbx2 regulation of Smad C-terminal phosphorylation}

As mentioned above, TGF $\beta$-induced nuclear accumulation and activation of Smad1 and Smad2 is mediated by phosphorylation of Serine residues at their C-termini [35]. We reasoned that Tbx2 might inhibit Smad activation via inhibition of Smad C-terminal phosphorylation. To test this possibility, animal cap explants derived from embryos injected with $t b \times 2$ RNA and cultured in the presence or absence of Activin were assayed at gastrula

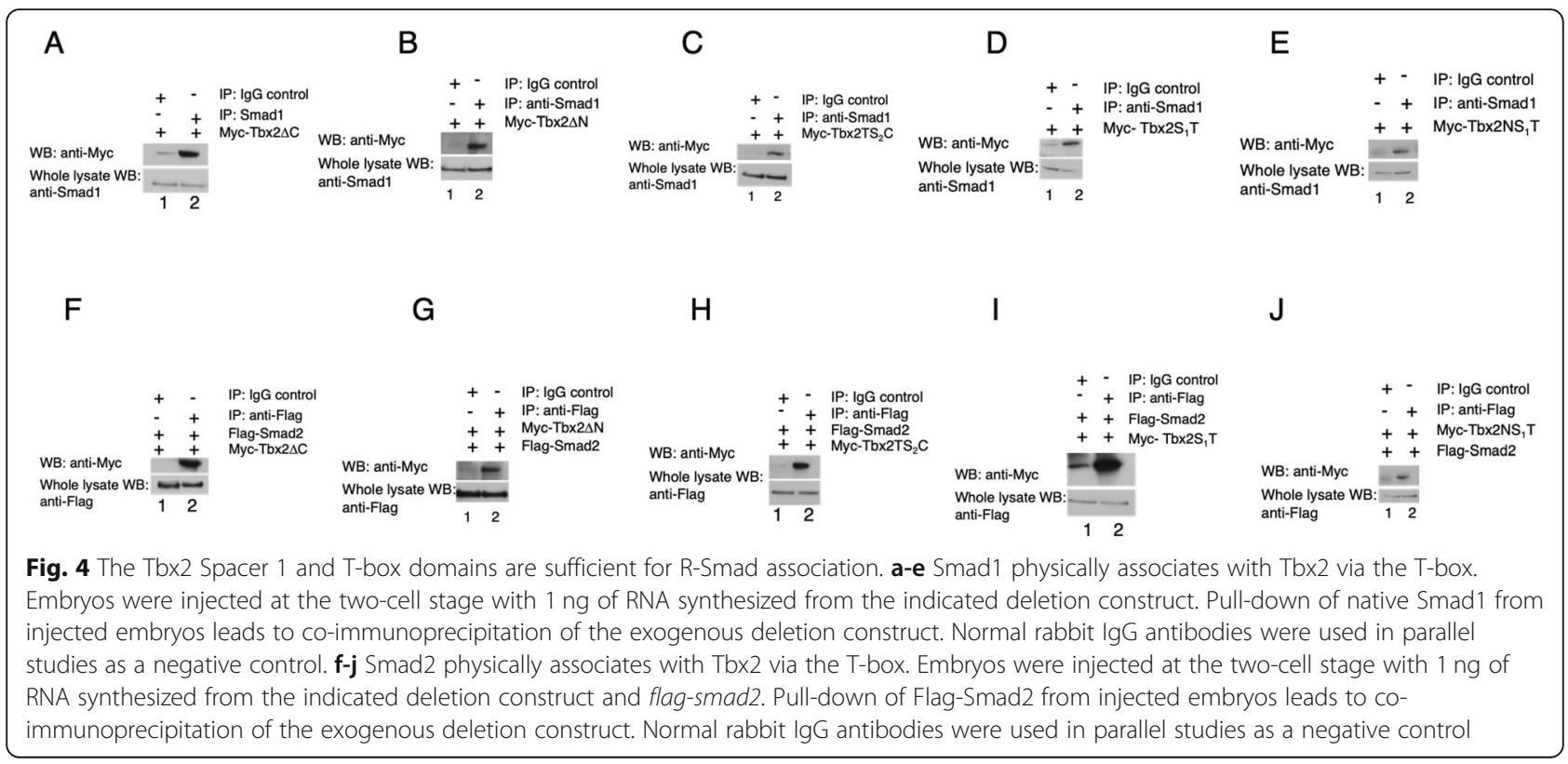


A

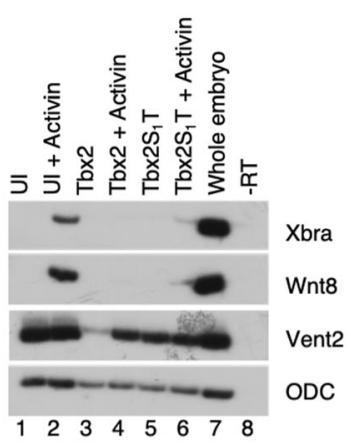

(

B

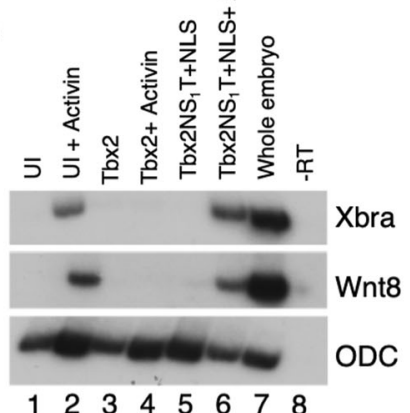

C

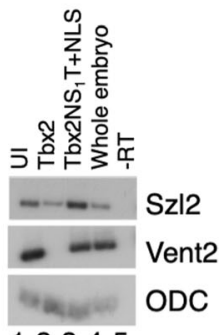

12345
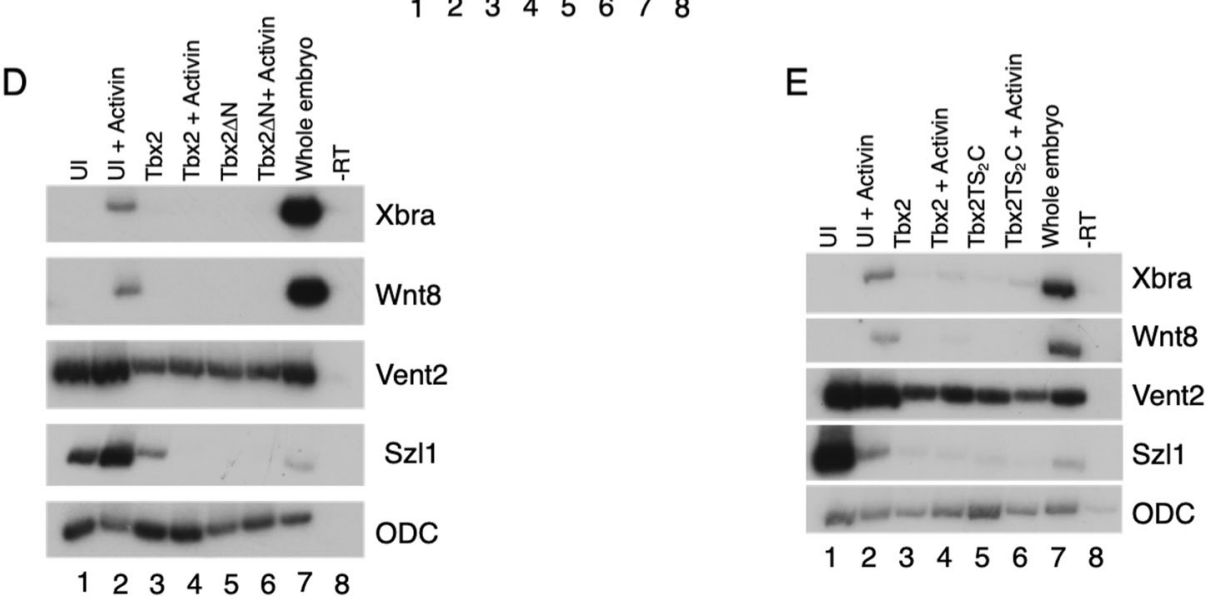

Fig. 5 Effects of Tbx2 deletion constructs on the BMP/GDF and Activin/Nodal pathways a) Embryos were injected with $2 \mathrm{ng}$ of $t b \times 2$ or tbx $2 S_{7} T$ in the animal pole at the two-cell stage. Animal caps were explanted at stage 8.5 . Activin was added $(2.5 \mathrm{ng} / \mathrm{ml})$ as indicated. b Embryos were injected with $2 \mathrm{ng}$ of tbx2 or tbx2NS $T_{1}$ in the animal pole at the two-cell stage. Animal caps were explanted at stage 8.5. Activin was added (2.5 $\mathrm{ng} / \mathrm{ml}$ ) as indicated. c Embryos were injected with $2 \mathrm{ng}$ of $t b \times 2$ or $t b \times 2 \mathrm{NS}_{1} T$ in the animal pole at the two-cell stage. Animal caps were explanted at stage 8.5. $\mathbf{d}$ Embryos were injected with $1 \mathrm{ng} t b \times 2$ or $t b \times 2 \Delta N$ in the animal pole at the two-cell stage. Animal caps were explanted at stage 8.5. Activin was added $(2.5 \mathrm{ng} / \mathrm{ml})$ as indicated e) Embryos were injected with $1 \mathrm{ng}$ tbx2 or tbx2 $\mathrm{TS}_{2} \mathrm{C}$ in the animal pole at the two-cell stage. Animal caps were explanted at stage 8.5 . Activin was added $(2.5 \mathrm{ng} / \mathrm{ml})$ as indicated

Anti-Smad2
Fig. 6 Tbx2 does not decrease levels of C-terminal phosphorylation of Smad1 and Smad2 a) Embryos were injected with 1 ng tbx2 at the two-
cell stage; animal caps were explanted at stage 8.5 and incubated in Activin $(2.5 \mathrm{ng} / \mathrm{ml})$, as indicated, until late gastrula stages. Uninjected
embryos were used in parallel studies. $\mathbf{b}$ Embryos were injected with $1 \mathrm{ng}$ tbx2 at the two-cell stage and animal caps were explanted at stage 8.5
and incubated until late gastrula stages. Uninjected embryos were used in parallel studies. $\mathbf{c}$ Quantification of data shown in B, indicating no
change in Smad1 protein levels or phosphorylation of Smad1 as a result of ectopic tbx2 expression


stages for embryological activity and for Smad Cterminal phosphorylation by Western blotting (Cell Signaling) [36]. Uninjected embryos were processed in parallel. Notably, we found that Tbx2 does not decrease Smad2 phosphorylation levels in the presence of Activin, indicating that $\mathrm{Tbx} 2$ does not inhibit Activin/Nodal signaling through hypophosphorylation of Smad2 Cterminal Serine residues (Fig. 6a). Similar experiments were performed to examine the potential regulation by Tbx2 on Smad1 C-terminal phosphorylation. In these studies, Smad1 C-terminal phosphorylation was similarly unaffected by the presence of ectopic Tbx2 (Fig. 6b, c). These studies demonstrate that Tbx2 does not inhibit TGF $\beta$ signaling via C-terminal dephosphorylation of Smad1 or Smad2.

\section{Tbx2 activity requires arginine 122}

The T-box protein Tbx20 mediates repressor activity independent of DNA binding [37]. We therefore questioned whether DNA-binding was necessary for Tbx2 activity. We thus attempted to separate the DNA binding activity of Tbx2 from the physical association of Tbx2 with R-Smads. Previous studies of T-box proteins have shown that Arginine 122 is necessary for Tbx2 DNA binding activity [38]. An Arginine to Alanine mutation in the T-box of Myc-Tbx2 (Myc-Tbx2R-A) abolishes repressor activity in both the BMP/GDF and Activin/Nodal branches of the TGF $\beta$ pathway (Fig. 7a). Co-immunoprecipitaion experiments with Myc-tagged Tbx2R-A, Smad1, and Smad2 show that Tbx2 associates with R-Smads even when DNA-binding activity is abolished (Fig. 7b,c). These data indicate that Tbx2 physically associates with R-Smads independent of DNA binding, and that this interaction is not sufficient for repression of TGF $\beta$ signaling.

\section{Discussion}

T-box transcription factors mediate cell specification and patterning in the early vertebrate embryo. Our results point to a central role for Tbx2-Smad interactions in the inhibition of both ventral and mesodermal fates. The inability of $\mathrm{Tbx}_{2} \mathrm{~S}_{1} \mathrm{~T}$ to consistently repress ventral markers, while effectively blocking mesoderm induction, indicates that different domains of Tbx2 may be necessary to repress the Activin/Nodal and BMP/GDF pathways. We find that the Tbx2 Spacer 1 and T-box domains are sufficient for interaction with R-Smads. Because the T-box is necessary for Tbx2 activity, it was not possible to inhibit R-Smad association without eliminating a domain presumably required for DNA binding. A

\section{B}

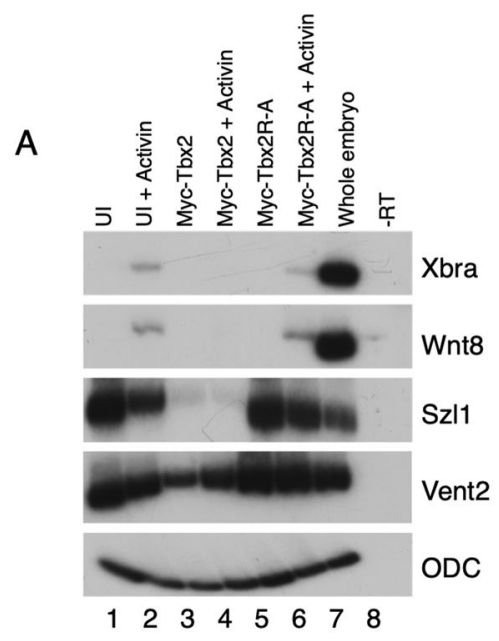

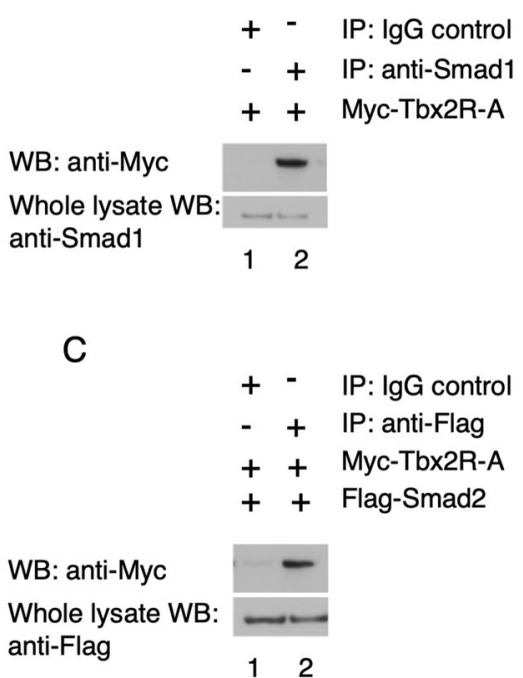

12

Fig. 7 DNA binding is necessary for Tbx2 repressor activity. a RT-PCR analysis of animal cap explants injected with Tbx2 DNA binding mutant construct. Embryos were injected with $1 \mathrm{ng}$ myc-tbx2R-A or myc-tbx2 at the two-cell stage; animal caps were explanted at stage 8.5 and incubated in Activin $(2.5 \mathrm{ng} / \mathrm{ml})$ where indicated until late gastrula stages. b Smad1 physically associates with Tbx2R-A. Embryos were injected at the two-cell stage with $1 \mathrm{ng}$ of RNA synthesized from Myc-Tbx2R-A. Pull-down of native Smad1 from injected embryos leads to coimmunoprecipitation of exogenous Myc-Tbx2R-A. Normal rabbit lgG antibodies was used in parallel studies as a negative control. c Smad2 physically associates with Myc-Tbx2R-A. Embryos were injected at the two-cell stage with $1 \mathrm{ng}$ myc-tbx2R-A and $1 \mathrm{ng}$ flag-smad2. Pull-down of Flag-Smad2 from injected embryos leads to co-immunoprecipitation of exogenous Myc-Tbx2R-A. Normal rabbit lgG antibodies were used in parallel studies as a negative control 
point mutation in the T-box of Tbx2 demonstrates that Tbx2 associates with R-Smads independently of DNA binding. Misexpression of the Tbx2 DNA-binding mutant does not repress ventral or mesodermal markers, indicating that repression of ventral and mesodermal markers requires DNA binding.

In a previous study, we demonstrated that Tbx2 dorsalizes ectoderm and is necessary and sufficient for the suppression of mesoderm and endoderm in the animal pole of the gastrula stage Xenopus laevis embryo [10]. Like Tbx2, several other repressors of mesodermal and ventral gene expression in the ectoderm function by inhibiting both the Activin/Nodal and BMP/GDF branches of the TGF $\beta$ signaling pathway $[8,39,40]$. In the TGF $\beta$ signaling pathway, R-Smad proteins are present in the cytoplasm until they are phosphorylated following ligand receptor binding, and translocate into the nucleus [35]. As knockdown of tbx2 in animal cap explants stimulates expression of mesodermal markers, it is possible that Tbx2 prevents low levels of phosphorylated R-Smads present in the nucleus from having an appreciable effect on mesendodermal and/or ventral gene expression.

Various T-box transcription factors such as Eomesodermin, Brachyury, and Tbx20 have been shown to associate with either Smad1 or Smad2 and have been shown to function in either the BMP/GDF or Activin/Nodal pathways [37, 41, 42]. Here, we describe a T-box protein that associates with both classes of R-Smad and that represses both branches of the TGF $\beta$ signaling network. The association between Brachyury and Smad1 requires BMP signaling and is necessary for the activation of Vent2.2 (Xom), a repressor of goosecoid [41]. If the association between Brachyury and Smad1 is attenuated, Brachyury activates goosecoid, and only high levels of both Brachyury and the BMP antagonist Noggin can activate goosecoid [41]. These results suggest that Brachyury activity is dependent on the level of BMP signaling, and subsequently, the levels of Smad1 in the nucleus. An analogous scenario possibly occurs in the presumptive ectoderm, whereby ventral Tbx2 activity is suppressed by high levels of nuclear Smad1.

The domains of Smad1 and Smad2 necessary for Tbx2 association remain unknown. Brachyury, Eomesodermin, and Tbx20 have all been shown to physically associate with R-Smads [37, 41, 42]. To our knowledge, the R-Smad domain(s) necessary for the association with Eomesodermin and Tbx20 are not defined. Brachyury associates via its N-terminus with Smad1 via the Smad1 C-terminus [41]. Sequence analysis does not show any appreciable alignment between the $\mathrm{N}$ terminus of Brachyury and any region of Tbx2. Additionally, unlike Tbx2, Brachyury does not associate with Smad2 [41].
T-box proteins have been shown to play an important role in a neuromesodermal bimodal "switch" to either promote mesodermal or neural gene expression at the expense of the other [43]. The current study and previous data from our group show that Tbx2 promotes neuralization at the expense of a mesendodermal fate [10]. Our data suggest that Tbx2 may not inhibit RSmad function directly; it is also possible that the Tbx2Smad association is necessary for Tbx2 repressor activity in the context of germ layer differentiation. Many transcription factors that are responsible for controlling cell fate commitment in developing embryos also regulate development of pluripotent stem cells [44, 45]. Identifying transcription factors necessary for germ layer differentiation, including Tbx2, and defining their mechanisms of action thus has far-reaching implications in multiple areas of biology.

\section{Conclusion}

During gastrulation, T-box transcription factors play important roles in cell fate specification [2, 3, 10, 30]. For the first time, we show physical association between Tbx2 and intracellular mediators of both the BMP/GDF and Activin/Nodal signaling pathways. Protein-protein interaction assays indicate that the Tbx2 T-box is sufficient for association with R-Smads; furthermore, structure/function analysis identified a novel repressor domain in Tbx2 located in either the first spacer or the T-box. Inhibition of DNA binding by Tbx2 blocks its ability to inhibit ventral and mesodermal fate. Our studies suggest a model in which Tbx2 physically associates with Smad1 or Smad2, represses transcription of BMP/ GDF or Activin/Nodal targets, and thus inhibits expression of ventral and mesodermal genes, respectively.

\section{Methods}

RNA preparation, explant dissection, and embryo culture

RNA was synthesized in vitro in the presence of cap analog using the mMessage mMachine kit (Ambion). Microinjection, explant dissection, and embryo culture were performed as described [3, 14-17]. All constructs were injected at a concentration of $1 \mathrm{ng} /$ embryo except in the experiments with $t b \times 2 N S_{1} T$. In this series of experiments, embryos were injected with $2 \mathrm{ng}$ /embryo of $t b \times 2 N S_{1} T$ or $2 \mathrm{ng}$ of $t b x 2$ ( $1 \mathrm{ng}$ of RNA injected into each cell at the two-cell stage). For all other experiments, where the constructs were injected with a total of $1 \mathrm{ng} / \mathrm{embryo}$, embryos injected at the two-cell stage were injected with $500 \mathrm{pg}$ into each cell. For all animal cap and marginal zone explant experiments, a minimum of five explants was used for each condition, and each experiment was performed at least three times; results were consistent between all trials. 


\section{Construct preparation}

To generate Myc-Tbx $2 \Delta \mathrm{C}$, six Myc epitope tags were added upstream of a Tbx $2 \Delta C$ construct, the latter containing amino acids $1-518$ of Tbx2 [10, 46]. To generate Tbx $2 \Delta \mathrm{N}$, amino acids 54-688 were subcloned into pCS2++. For the Myc-Tbx $2 \Delta \mathrm{N}$, DNA encoding amino acids 54-688 were subcloned into pCS2MT (constructed by D. L. Turner and R. A. W. Rupp). For Tbx2NS 1 T, amino acids 290-688 were deleted from Tbx2 in pCS2+. The same amino acids were deleted from Myc-Tbx2 to generate Myc-Tbx2 $\mathrm{NS}_{1} \mathrm{~T}$ (Genewiz). In this construct and all subsequent constructs with the Tbx2 T-box at the $\mathrm{C}$ terminus, ten amino acids from spacer 2 were added to include the nuclear localization sequence [47]. To 16 generate $\mathrm{Tbx}_{2} \mathrm{TS}_{2} \mathrm{C}$, amino acids 1-54 were deleted from Tbx2 in pCS2+. The same amino acids were deleted in Myc-Tbx2 to generate Myc-Tbx2 $\mathrm{TS}_{2} \mathrm{C}$ (Genewiz). To construct $\mathrm{Tbx}_{2} \mathrm{~S}_{1} \mathrm{~T}$ and $\mathrm{Myc}-\mathrm{Tbx} 2 \mathrm{~S}_{1} \mathrm{~T}$, amino acids 290-688 were deleted from $\mathrm{Tbx} 2 \Delta \mathrm{N}$ and $\mathrm{MycTbx} 2 \Delta \mathrm{N}$, respectively. Myc-Tbx2R-A was generated by a single amino acid mutation of Arginine 122 to Alanine (AGG to GCT) in Myc-Tbx2 (Genewiz) [38]. Flag-Smad2 was purchased from Addgene (plasmid \#14042). Flag-Smad4 was a gift from Dr. Gerald Thomsen [48].

\section{Reverse transcription-polymerase chain reaction (RT-PCR)}

Xenopus laevis embryos were staged according to Nieuwkoop and Faber, 1967 and harvested at appropriate stages according to morphological criteria. RNA was prepared using RNA Bee RNA isolation reagent (Tel-Test Inc.). RT-PCR was performed as described (Wilson and Hemmati-Brivanlou, 1995). All primer sequences are as described: ODC, Xbra, Wnt8, chordin, and goosecoid [9]; Sizzled1 [49]; Sizzled2 [50]; Bmp4 [51]; Xvent2 [52].

\section{Western blot analysis}

Western blot analysis was performed largely as described [53]. Animal caps (10-15 per condition) were lysed in $5 \mathrm{ul} /$ animal cap of lysis buffer $(150 \mathrm{mM} \mathrm{NaCl}, 20 \mathrm{mM}$ Tris $\mathrm{pH} 7.5,1 \%$ Nonidet P-40, $1 \mathrm{mM}$ EDTA, and 1 protease and phosphatase inhibitor tablet $/ 10 \mathrm{ml}$ of buffer) (Thermofisher) [53]. After incubation on ice for $30 \mathrm{~min}$, animal cap lysates were centrifuged at $4{ }^{\circ} \mathrm{C}$ for $5 \mathrm{~min}$ at $14,000 \mathrm{~g}$. Clear supernatant was retained. 5-15 ul of supernatant was run for each sample. Antibodies against phospho-Smad1/5 (S463/465) (Cell Signaling Technology), Smad1 (Cell Signaling Technology), PhosphoSmad2 (S465/467) (Cell signaling technology), Smad2/3 (Cell signaling technology) and GAPDH (Sigma) were all used at 1:1000 dilution. Secondary antibodies (donkey anti-rabbit IgG, or donkey anti-mouse IgG) coupled to horseradish peroxidase (Jackson ImmunoResearch) were used at 1:10,000 dilution. Bands were subjected to densitometric analysis and graphed.

\section{Co-immunoprecipitation}

RNA from all Myc-tagged constructs was injected into early cleavage stages embryos. Injected embryos were harvested at late gastrula stages. Co-immunoprecipitation experiments were performed largely as described [53]. Embryos were lysed in 10ul/embryo of lysis buffer (150 mM NaCl, $20 \mathrm{mM}$ Tris $\mathrm{pH} 7.5,1 \%$ Nonidet P-40, $1 \mathrm{mM}$ EDTA, and 1 protease inhibitor tablet $/ 10 \mathrm{ml}$ of buffer) (Thermofisher) [53]. After incubation on ice for $30 \mathrm{~min}$, embryo lysates were centrifuged at $4{ }^{\circ} \mathrm{C}$ for $5 \mathrm{~min}$ at $14,000 \mathrm{~g}$. Clear supernatant was retained and then split equally into control and experimental samples. $10 \mathrm{ul}$ of clear supernatant was removed as "input" from each sample. Embryo lysates were incubated with rotation overnight at $4{ }^{\circ} \mathrm{C}$ with either antiSmad1 $(333 \mu \mathrm{g} / \mathrm{ml})$ or anti-Flag $(800 \mu \mathrm{g} / \mathrm{ml})$ antibodies at $1: 150$ dilution or normal Rabbit IgG $(1 \mathrm{mg} / \mathrm{ml})$ with the IgG normalized to experimental samples (Cell Signaling Technology), followed by incubation with Dynabeads Protein G (Novex) with rotation at $4{ }^{\circ} \mathrm{C}$ for one hour. Samples were washed 6 times with 200 ul of lysis buffer and eluted with 20ul of $1 \mathrm{X}$ NuPage LDS sample buffer and $5 \mathrm{ul}$ of $.5 \mathrm{M}$ dithiothreitol. The elution was subject to SDS-PAGE. Antibodies against Myc (Sigma) were used to probe the blot at 1:1000 dilution. Secondary antibodies (donkey anti-mouse IgG) coupled to horseradish peroxidase (Jackson ImmunoResearch) were used at 1:10,000 dilution.

\section{Supplementary information}

Supplementary information accompanies this paper at https://doi.org/10. 1186/s12860-020-00282-1.

Additional file 1: Figure 1- unprocessed data RT-PCR gels shown in figure 1

Additional file 2: Figure $2 \mathrm{~A}$ - unprocessed data. Western blots shown in Figure 2A. Figure 2B- unprocessed data Western blots shown in 2B. Figure 2C- unprocessed data RT-PCR gel shown in Figure 2C. Figure 2Dunprocessed data Western blots shown in Figure 2D.

Additional file 3: Figure 4A- unprocessed data. Western blots shown in figure 4A. Figure 4B- unprocessed data Western blots shown in figure 4B. Figure 4C- unprocessed data Western blots shown in figure 4C. Figure 4D- unprocessed data Western blots shown in figure 4D. Figure 4Eunprocessed data Western blots shown in figure 4E. Figure 4Funprocessed data Western blots shown in figure 4F. Figure 4Gunprocessed data Western blots shown in figure 4G. Figure $4 \mathrm{H}-$ unprocessed data Western blots shown in figure $4 \mathrm{H}$. Figure $4 \mathrm{I}-$ unprocessed data Western blots shown in figure 4I. Figure 4Junprocessed data Western blots shown in figure 4J

Additional file 4: Figure 5A- unprocessed data. RT-PCR gels shown in figure $5 \mathrm{~A}$. Figure $5 \mathrm{~B}$ - unprocessed data RT-PCR gels shown in figure $5 \mathrm{~B}$. Figure 5C- unprocessed data. RT-PCR gels shown in figure 5C. Figure 5Dunprocessed data. RT-PCR gels shown in figure 5D. Figure 5E- unprocessed data. RT-PCR gels shown in figure $5 \mathrm{E}$

Additional file 5: Figure 6A- unprocessed data. Western blots shown in figure $6 \mathrm{~A}$. Figure $6 \mathrm{~B}$ - unprocessed data Western blots shown in figure $6 \mathrm{~B}$

Additional file 6: Figure 7A- unprocessed data. RT-PCR gels shown in figure 7A. Figure 7B- unprocessed data Western blots shown in figure 7B. Figure $7 C$ - unprocessed data Western blots shown in figure $7 C$ 


\section{Abbreviations}

TGF $\beta$ : Transforming growth factor beta; BMP: Bone morphogenetic protein: GDF: Growth differentiation factor

\section{Acknowledgements}

We thank Dr. Gerald Thomsen for the Flag-Smad4 plasmid. We thank current lab members for thoughtful discussion and input.

\section{Authors' contributions}

SR, ST, and DCW conceived and designed the project. SR and PK performed the experiments. SR and DCW wrote, revised, and finalized the manuscript. All authors have read and approved the final manuscript.

\section{Funding}

This work is supported by PHS Grant R15GM124577 (D.C.W.) and with funds from Queens College of the City University of New York and the Professional Staff Congress-City University of New York. The funding bodies played no role in the design of the study, the collection, analysis, and interpretation of data and/or in writing the manuscript.

\section{Availability of data and materials}

All original gels and blots have been uploaded as Additional File 1, Additional File 2A, Additional File 2B, Additional File 2C, Additional File 2D, Additional File 3A, Additional File 3B, Additional File 3C, Additional File 3D, Additional File 3E, Additional File 3F, Additional File 3G, Additional File 3H, Additional File 3l, Additional File $3 \mathrm{~J}$, Additional File 4A, Additional File 4B, Additional File 4C, Additional File 4D, Additional File 4E, Additional File 5A, Additional File 5B, Additional File 6A, Additional File 6B, and Additional File 6C.

\section{Ethics approval and consent to participate}

All procedures were approved by the Queens College IACUC committee, protocol \#160

\section{Consent for publication}

Not applicable.

\section{Competing interests}

The authors declare no conflicts of interest.

\section{Received: 2 January 2020 Accepted: 11 May 2020}

\section{Published online: 28 May 2020}

\section{References}

1. Horb ME, Thomsen GH. A vegetally localized T-box transcription factor in Xenopus eggs specifies mesoderm and endoderm and is essential for embryonic mesoderm formation. Development. 1997;124(9):1689-98.

2. Kofron M, Demel T, Xanthos J, Lohr J, Sun B, Sive H, et al. Mesoderm induction in Xenopus is a zygotic event regulated by maternal VegT via TGFbeta growth factors. Development. 1999;126(24):5759-70.

3. Xanthos JB, Kofron M, Wylie C, Heasman J. Maternal VegT is the initiator of a molecular network specifying endoderm in Xenopus laevis. Development. 2001;128(2):167-80.

4. Heasman J. Patterning the early Xenopus embryo. Development. 2006; 133(7):1205-17.

5. Hemmati-Brivanlou A, Melton DA. Inhibition of activin receptor signaling promotes neuralization in Xenopus. Cell. 1994;77(2):273-81.

6. Reich $\mathrm{S}$, Weinstein DC. Repression of inappropriate gene expression in the vertebrate embryonic ectoderm. Genes. 2019;10(11):895.

7. Bates TJD, Vonica A, Heasman J, Brivanlou AH, Bell E. Coco regulates dorsoventral specification of germ layers via inhibition of TGF $\beta$ signalling. Development. 2013;140(20):4177-81.

8. Bell E, Muñoz-Sanjuán I, Altmann CR, Vonica A, Brivanlou AH. Cell fate specification and competence by coco, a maternal BMP, TGFbeta and Wht inhibitor. Development. 2003;130(7):1381-9.

9. Suri $C$, Haremaki T, Weinstein DC. Xema, a foxi-class gene expressed in the gastrula stage Xenopus ectoderm, is required for the suppression of mesendoderm. Development. 2005;132(12):2733-42..

10. Teegala $S$, Chauhan R, Lei E, Weinstein DC. Tbx2 is required for the suppression of mesendoderm during early Xenopus development. Dev Dyn. 2018;247(7):903-13.
11. Showell C, Binder O, Conlon FL. T-box genes in early embryogenesis. Dev Dyn. 2004;229(1):201-18.

12. Kispert A, Ortner H, Cooke J, Herrmann BG. The Chick Brachyury gene: developmental expression pattern and response to axial induction by localized Activin. Dev Biol. 1995 Apr 1;168(2):406-15.

13. Gluecksohn-Schoenheimer $\mathrm{S}$. The development of two tailless mutants in the house mouse. Genetics. 1938;23(6):573-84.

14. Christoffels VM, Hoogaars WMH, Tessari A, Clout DEW, Moorman AFM, Campione M. T-box transcription factor Tbx2 represses differentiation and formation of the cardiac chambers. Dev Dyn. 2004;229(4):763-70.

15. Dastjerdi A, Robson L, Walker R, Hadley J, Zhang Z, Rodriguez-Niedenführ M et al. Tbx1 regulation of myogenic differentiation in the limb and cranial mesoderm. Dev Dyn. 2007;236(2):353-63.

16. Lüdtke TH-W, Farin HF, Rudat C, Schuster-Gossler K, Petry M, Barnett P, et al. Tbx2 controls lung growth by direct repression of the cell cycle inhibitor genes Cdkn1a and Cdkn1b. PLoS Genet. 2013;9(1):e1003189.

17. Lüdtke TH-W, Christoffels VM, Petry M, Kispert A. Tbx3 promotes liver bud expansion during mouse development by suppression of cholangiocyte differentiation. Hepatology. 2009;49(3):969-78.

18. Papaioannou VE. The T-box gene family: emerging roles in development, stem cells and cancer. Development. 2014;141(20):3819-33.

19. Wilson V, Conlon FL. The T-box family. Genome Biol. 2002;3(6): reviews3008.1-7.

20. Conlon FL, Fairclough L, Price BM, Casey ES, Smith JC. Determinants of T box protein specificity. Development. 2001;128(19):3749-58.

21. Plageman TF, Yutzey KE. T-box genes and heart development: putting the "T" in heart. Dev Dyn. 2005;232(1):11-20.

22. Zaragoza MV, Lewis LE, Sun G, Wang E, Li L, Said-Salman I, et al. Identification of the TBX5 transactivating domain and the nuclear localization signal. Gene. 2004 Apr 14;330:9-18.

23. Herrmann BG, Labeit S, Poustka A, King TR, Lehrach H. Cloning of the T gene required in mesoderm formation in the mouse. Nature. 1990; 343(6259):617-22.

24. Wilson PA, Hemmati-Brivanlou A. Induction of epidermis and inhibition of neural fate by bmp-4. Nature. 1995;376(6538):331-3.

25. Baker CV, Bronner-Fraser M. Vertebrate cranial placodes I, Embryonic induction. Dev Biol. 2001;232(1):1-61.

26. Mancilla A, Mayor R. Neural crest formation in Xenopus laevis: mechanisms of Xslug induction. Dev Biol. 1996;177(2):580-9.

27. Weinstein DC, Hemmati-Brivanlou A. Neural induction in Xenopus laevis: evidence for the default model. Curr Opin Neurobiol. 1997;7(1):7-12.

28. Abdollah S, Macías-Silva M, Tsukazaki T, Hayashi H, Attisano L, Wrana JL. TbetaRI phosphorylation of Smad2 on Ser465 and Ser467 is required for Smad2-Smad4 complex formation and signaling. J Biol Chem. 1997;272(44): 27678-85.

29. Wrana JL, Attisano L, Wieser R, Ventura F, Massagué J. Mechanism of activation of the TGF-beta receptor. Nature. 1994;370(6488):341-7.

30. Smith JC, Price BMJ, Green JBA, Weigel D, Herrmann BG. Expression of a xenopus homolog of Brachyury (T) is an immediate-early response to mesoderm induction. Cell. 1991;67(1):79-87.

31. Cho KW, Blumberg B, Steinbeisser H, De Robertis EM. Molecular nature of Spemann's organizer: the role of the Xenopus homeobox gene goosecoid. Cell. 1991;67(6):1111-20.

32. Christian JL, McMahon JA, McMahon AP, Moon RT. Xwnt-8, a Xenopus Wnt1/int-1-related gene responsive to mesoderm-inducing growth factors, may play a role in ventral mesodermal patterning during embryogenesis. Development. 1991;111(4):1045-55.

33. Sasai Y, Lu B, Steinbeisser H, Geissert D, Gont LK, De Robertis EM. Xenopus chordin: a novel dorsalizing factor activated by organizer-specific homeobox genes. Cell. 1994;79(5):779-90.

34. Lagna G, Hata A, Hemmati-Brivanlou A, Massagué J. Partnership between DPC4 and SMAD proteins in TGF-beta signalling pathways. Nature. 1996; 383(6603):832-6.

35. Macías-Silva M, Abdollah S, Hoodless PA, Pirone R, Attisano L, Wrana JL. MADR2 is a substrate of the TGFbeta receptor and its phosphorylation is required for nuclear accumulation and signaling. Cell. 1996;87(7):1215-24.

36. Simeoni I, Gurdon JB. Interpretation of BMP signaling in early Xenopus development. Dev Biol. 2007;308(1):82-92.

37. Singh R, Horsthuis T, Farin HF, Grieskamp T, Norden J, Petry M, et al. Tbx20 interacts with smads to confine tbx2 expression to the atrioventricular canal. Circ Res. 2009;105(5):442-52. 
38. Sinha S, Abraham S, Gronostajski RM, Campbell CE. Differential DNA binding and transcription modulation by three T-box proteins, T, TBX1 and TBX2. Gene. 2000;258(1-2):15-29.

39. Casellas R, Brivanlou AH. Xenopus Smad7 inhibits both the activin and BMP pathways and acts as a neural inducer. Dev Biol. 1998;198(1):1-12.

40. Xu S, Cheng F, Liang J, Wu W, Zhang J. Maternal xNorrin, a canonical Wnt signaling agonist and TGF- $\beta$ antagonist, controls early neuroectoderm specification in Xenopus. PLoS Biol. 2012;10(3):e1001286.

41. Messenger NJ, Kabitschke C, Andrews R, Grimmer D, Núñez Miguel R, Blundell $T L$, et al. Functional specificity of the Xenopus T-domain protein Brachyury is conferred by its ability to interact with Smad1. Dev Cell. 2005; 8(4):599-610.

42. Picozzi P, Wang F, Cronk K, Ryan K. Eomesodermin requires transforming growth factor-beta/activin signaling and binds Smad2 to activate mesodermal genes. J Biol Chem. 2009;284(4):2397-408.

43. Gentsch GE, Owens NDL, Martin SR, Piccinelli P, Faial T, Trotter MWB, et al. In vivo T-box transcription factor profiling reveals joint regulation of embryonic neuromesodermal bipotency. Cell Rep. 2013 Sep 26;4(6):1185-96.

44. Pei D. Regulation of pluripotency and reprogramming by transcription factors. J Biol Chem. 2009 Feb 6;284(6):3365-9.

45. Takahashi K, Yamanaka S. Induction of pluripotent stem cells from mouse embryonic and adult fibroblast cultures by defined factors. Cell. 2006 Aug 25;126(4):663-76

46. Cho G-S, Choi S-C, Park EC, Han J-K. Role of Tbx2 in defining the territory of the pronephric nephron. Development. 2011 Feb;138(3):465-74.

47. Carlson H, Ota S, Campbell CE, Hurlin PJ. A dominant repression domain in Tbx3 mediates transcriptional repression and cell immortalization: relevance to mutations in Tbx3 that cause ulnar-mammary syndrome. Hum Mol Genet. 2001;10(21):2403-13.

48. Kavsak P, Rasmussen RK, Causing CG, Bonni S, Zhu H, Thomsen GH, et al. Smad7 binds to Smurf2 to form an E3 ubiquitin ligase that targets the TGF beta receptor for degradation. Mol Cell. 2000;6(6):1365-75.

49. Sridharan J, Haremaki T, Jin Y, Teegala S, Weinstein DC. Xmab2113 mediates dorsoventral patterning in Xenopus laevis. Mech Dev. 2012;129(5-8):136-46.

50. Jin Y, Weinstein DC. Pitx1 regulates cement gland development in Xenopus laevis through activation of transcriptional targets and inhibition of BMP signaling. Dev Biol. 2018:437(1):41-9.

51. Fainsod A, Deissler K, Yelin R, Marom K, Epstein M, Pillemer G, et al. The dorsalizing and neural inducing gene follistatin is an antagonist of BMP-4. Mech Dev. 1997;63(1):39-50.

52. Miyazaki A, Ishii K, Yamashita S, Nejigane S, Matsukawa S, Ito Y, et al. mNanog possesses dorsal mesoderm-inducing ability by modulating both BMP and Activin/nodal signaling in Xenopus ectodermal cells. PLoS One. 2012:7(10):e46630.

53. Hama J, Suri C, Haremaki T, Weinstein DC. The molecular basis of Src kinase specificity during vertebrate mesoderm formation. J Biol Chem. 2002; 277(22):19806-10.

\section{Publisher's Note}

Springer Nature remains neutral with regard to jurisdictional claims in published maps and institutional affiliations.

Ready to submit your research? Choose BMC and benefit from:

- fast, convenient online submission

- thorough peer review by experienced researchers in your field

- rapid publication on acceptance

- support for research data, including large and complex data types

- gold Open Access which fosters wider collaboration and increased citations

- maximum visibility for your research: over $100 \mathrm{M}$ website views per year

At BMC, research is always in progress.

Learn more biomedcentral.com/submissions 